\title{
The relation of secondary sex ratio and miscarriage history with Toxoplasma gondii infection
}

\author{
Saeedeh Shojaee ${ }^{1 *}$, Aref Teimouri ${ }^{1,2}$, Hossein Keshavarz ${ }^{1}$, Sanaz Jafarpour Azami ${ }^{1}$ and Sahar Nouri ${ }^{3}$
}

\begin{abstract}
Background: Toxoplasma gondii is a protozoan parasite with worldwide distribution, infecting a broad-range of humans and warm-blooded animals. In the current study, role of this parasite on secondary sex ratio and risk of miscarriage was investigated.
\end{abstract}

Methods: In this cross-sectional study, 850 cord blood samples were collected in Tehran, Iran, 2014-2015. Enzyme-linked immunosorbent assay (ELISA) was used to assess anti-Toxoplasma lgG in samples. Information such as sex of the neonates and age, number of previous pregnancies and history of miscarriage of the mothers were recorded in questionnaires. Logistic regression analysis was used to assess the possible relationship between the latent toxoplasmosis and the highlighted parameters.

Results: Logistic regression analysis showed that the odds of having a male neonate in seropositive women is nearly $64 \%$ higher than that in seronegative women $\left(\mathrm{OR}=1.64, \mathrm{Cl}_{95}=1.16-2.33, P=0.005\right)$. The odds ratio of having male neonate increased to $2.10\left(\mathrm{Cl}_{95}=1.24-3.57, P=0.006\right)$ in high-titer seropositive women, compared to that in seronegative control group. The odds of having a miscarriage history was approximately two and a half times greater in seropositive women than in seronegative ones $\left(\mathrm{OR}=2.45, \mathrm{Cl}_{95}=1.56-3.87, P<0.001\right)$. The odds ratio of having miscarriage increased to $2.76\left(\mathrm{Cl}_{95}=1.61-4.73, P<<.001\right)$ in low-titer seropositive women, compared to that in seronegative control group.

Conclusion: Results of the current study have shown that $T$. gondii infection affects secondary sex ratio in human offspring and can be addressed as one of the major miscarriage causes in women.

Keywords: Toxoplasma gondii, Secondary sex ratio, Miscarriage, Cord blood serum, ELISA

\section{Background}

Toxoplasmosis is one of the most prevalent parasitic diseases, caused by a coccidian protozoan, Toxoplasma gondii [1]. Prevalence of T. gondii infection varies $10-80 \%$ in various regions of the world. Large differences have also been reported in Iran, with a prevalence of $39.8 \%$ in Golestan Province and $28.8 \%$ in Kerman Province [2, 3]. The main routes of human infection include consumption of raw or undercooked meat containing tissue cysts and ingestion of oocysts via contaminated waters or vegetables [4]. Vertical transmission of rapidly dividing tachyzoites

\footnotetext{
* Correspondence: shojaee1980@yahoo.com

${ }^{1}$ Department of Medical Parasitology and Mycology, School of Public Health, Tehran University of Medical Sciences, P.O. Box: 1417613191, Pour Sina Street, Ghods Avenue, Enghelab Avenue, Tehran, Iran

Full list of author information is available at the end of the article
}

from the pregnant mother to developing fetus is the other route of human infection. This infection route could lead to abortion, chorioretinitis or serious developmental disorders such as hydrocephaly and microcephaly [5]. Therefore, the accurate diagnosis of acute maternal toxoplasmosis in pregnant women is critical [6]. The acquired T. gondii infection in immunocompetent hosts is usually benign and results in latent infections with formation of cysts in brain, lungs and other tissues [7]. Latent toxoplasmosis is clinically asymptomatic but may be complicated by the increased risk of psychiatric and neurological abnormalities and personality changes such as bipolar disorder, obsessive-compulsive disorder, recurrent migraine, cryptic epilepsy, autism, suicide attempt, homicide and brain tumor [8]. 
The secondary sex ratio (the ratio of males to females at birth) is nearly 0.51 in human [9], which is affected by factors including age of parents [10], stress, immunosuppression, paternal endocrine disruption such as diabetes [11-13] and socioeconomic status of the parents [14]. Until now, three studies have assessed the effects of latent Toxoplasma infection on sex ratio at birth in humans and mice and all three found significant effects [15-17]. In contrast, effects of latent toxoplasmosis on risk of miscarriage are still being discussed by researchers [18-20]. Therefore, the present study was carried out to assess possible effects of $T$. gondii infection on secondary sex ratio and risk of miscarriage in 850 cord blood serum samples from delivered women in Tehran, Iran, 2014-2015.

\section{Methods}

\section{Patients}

In this cross-sectional study, 850 cord blood samples were collected in Tehran, Iran, 2014-2015. Sera were separated from the whole blood samples and stored at $20{ }^{\circ} \mathrm{C}$ until use. Information such as sex of the neonates and age, number of previous pregnancies and history of miscarriage of the women were recorded in questionnaires and used for statistical analysis.

\section{Serological tests}

Enzyme-linked immunosorbent assay (ELISA) was used to assess anti-Toxoplasma IgG in cord blood serum samples. The cut off value of optical density (OD) was calculated based on a protocol by Hillyer et al. [21]. Optical density of each sample was compared to the cut off value and recorded as positive or negative result.

\section{Preparation of soluble antigens of $T$. gondii}

Antigens were prepared as previously described [22]. Briefly, tachyzoites of $T$. gondii, $\mathrm{RH}$ strain, were inoculated into peritoneum cavity of BALB/c mice. After three days, the tachyzoites were harvested by peritoneum wash, then washed for three times, sonicated and centrifuged at $14000 \mathrm{~g}$ for $1 \mathrm{~h}$ at $4{ }^{\circ} \mathrm{C}$. Soluble antigens were collected and protein densities were assessed using Bradford method.

\section{Enzyme-linked immunosorbent assay (ELISA)}

In general, 96-well microplates (Nunk, Germany) were coated with $5 \mu \mathrm{g} / \mathrm{ml}$ of the soluble antigen of $T$. gondii, $\mathrm{RH}$ strain, and stored at $4{ }^{\circ} \mathrm{C}$ overnight. Cord blood serum samples were diluted 1:200 in PBST (phosphate buffered saline, tween 20) and added to each well of the microplates. After $1 \mathrm{~h}$ of incubation and three times of wash, $100 \mu \mathrm{l}$ of anti-human IgG conjugated with horseradish peroxidase (HRP) (Dako, Denmark) were added to the wells in dilutions of 1:500 in PBST. After incubation and wash steps, substrate of ortho-phenylenediamine (OPD) (Sigma-Aldrich, USA) was added to the wells. Reactions were stopped by adding a $20 \%$ sulfuric acid solution and the OD was recorded using an automated ELISA reader (Biotek, USA) at $490 \mathrm{~nm}$ [23].

\section{Statistical analysis}

Statistical analysis was carried out using SPSS Software v.21.0 (IBM Analytics, USA) [24]. Association between the sex of newborns (binary) or miscarriage history (binary) as dependent variables and two independent variables including Toxoplasma-seropositivity (binary) and age of the mothers (continuous) was assessed using logistic regression model. Furthermore, multiple logistic regression analysis was used to control the effect of potential confounding factors on the sex of neonates and history of miscarriage. Data description was carried out by calculating frequencies and 95\% confidence intervals. Differences were considered as significant when $P \leq 0.05$.

\section{Results}

Of 850 cord blood serum samples, 166 samples were positive for anti-Toxoplasma IgG; therefore, the overall anti-Toxoplasma antibody prevalence was $19.5 \%$ in this study. The average age of the participants was approximately 28.7 years with $95 \%$ confidence interval (28.4-29.1). Participants were divided into four age groups of $\leq 20,21-25,26-30$ and $\geq 31$. The majority of the pregnancies $(334 / 850,39.3 \%)$ occurred between 26 and 30 years of age. According to the age of women, the prevalence of anti-Toxoplasma IgG in 850 cord blood serum samples of participants was as follows: $\leq 20$ age group, $7 / 27$ (25.9\%); early 20s, 43/189 (22.8\%); late 20s, 60/334 (18\%); and $\geq 31$ age group, 56/300 (18.7\%) (Fig. 1).

The highest frequency of miscarriage in Toxoplasma-positive and Toxoplasma-negative subjects was observed in $\geq 31$ age group (Fig. 2), however, the association between the prevalence of toxoplasmosis and age of the women was not statistically significant $(P=0.4)$. Furthermore, no significant associations were seen between the miscarriage history and age of the women in seropositive participants $(P=0.15)$. Of 850 studied pregnant women, 444 delivered male neonates and 99 had a history of miscarriage.

\section{Association of anti-Toxoplasma lgG with sex ratio}

The Toxoplasma-seropositivity was significantly associated with having a male neonate $\left(\mathrm{OR}=1.64, \mathrm{CI}_{95}=\right.$ 1.16-2.33, $P=0.005)$; 103 out of 166 (62.1\%) newborns from seropositive mothers were males while 341 out of 684 (49.9\%) newborns from seronegative mothers were males. The OR of having male neonates increased up to $2.10\left(\mathrm{CI}_{95}=1.24-3.57, P=0.006\right)$ in seropositive women 


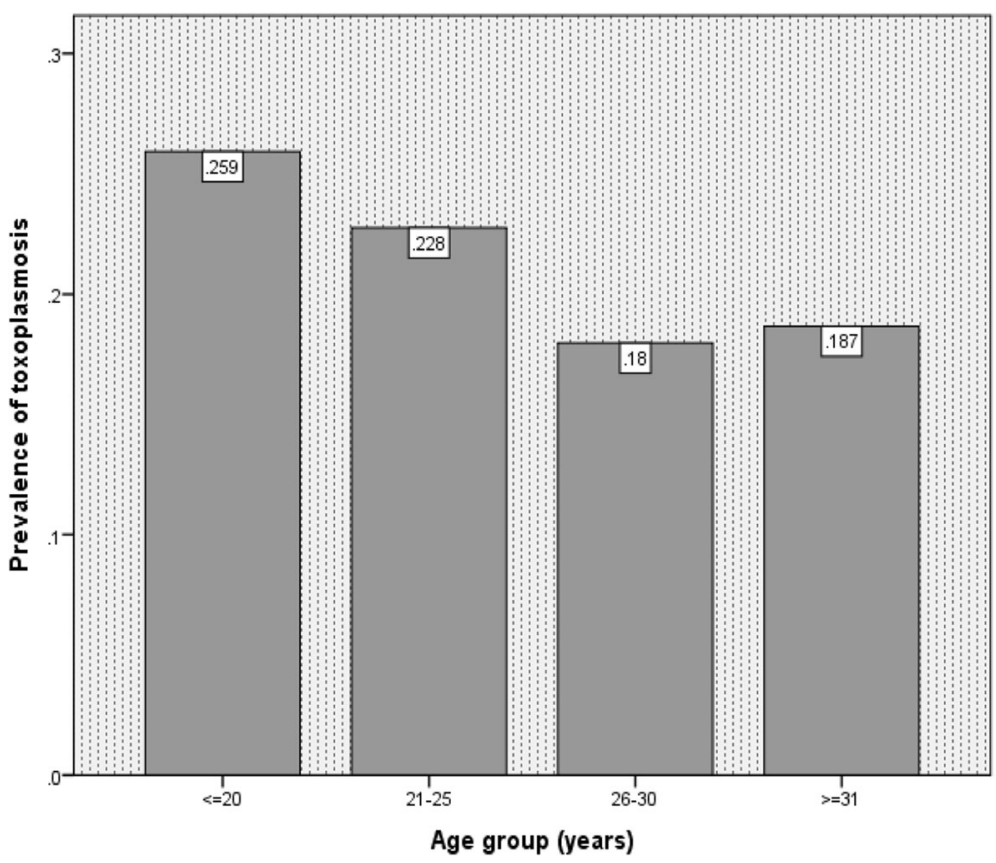

Fig. 1 Prevalence of anti-Toxoplasma lgG in 850 cord blood serum samples in particular age groups of participants using ELISA

with a high concentration of anti-Toxoplasma antibodies (OD > 0.75), compared to that in Toxoplasma-negative group. No significant differences were seen in OR of having male neonates in low-titer group $(\mathrm{OD} \leq 0.75)$, compared to that in negative control group $(\mathrm{OR}=1.4$, $\mathrm{CI}_{95}=0.91-2.16, P=0.12$ ).

Results from the multiple logistic regression analysis showed that the Toxoplasma-seropositivity was significantly associated with having a male neonate $\left(\mathrm{OR}=1.66, \mathrm{Cl}_{95}=\right.$ 1.16-2.35, $P=0.005$ ) after controlling for effects of miscarriage history in the model. Furthermore, the OR of having male neonates in high-titer and low-titer groups of seropositive women was $2.12\left(\mathrm{CI}_{95}=1.25-3.6, P=\right.$ $0.006)$ and 1.4 $\left(\mathrm{CI}_{95}=0.91-2.16, P=0.12\right)$ respectively, compared to that in toxoplasma-seronegative women. Association between the age of women and sex of the

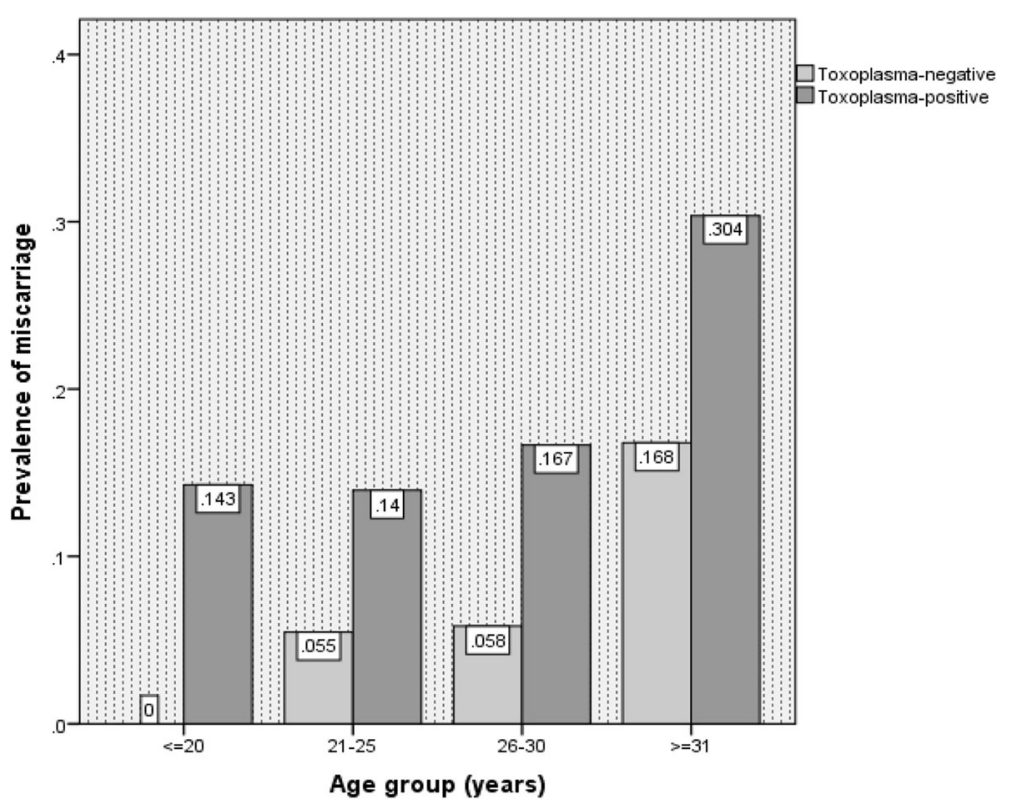

Fig. 2 Prevalence of miscarriage in particular age groups of 166 Toxoplasma-positive and 684 Toxoplasma-negative subjects using ELISA 
neonates was not statistically significant $\left(\mathrm{OR}=0.98, \mathrm{CI}_{95}\right.$ $=0.9-1, P=0.19$ ).

\section{Association between anti-Toxoplasma lgG and miscarriage} In 99 women with miscarriage history (mean age 30.87 years, $\mathrm{CI}_{95}=29.9-31.82$ ), anti-Toxoplasma IgG antibodies were found in $34.3 \%$ of cases while in 751 women without miscarriage history (mean age 28.42 years, $\mathrm{Cl}_{95}=$ 28.15-28.81) the anti-Toxoplasma IgG antibodies were found in $17.6 \%$ of cases. Results of the logistic regression showed that Toxoplasma-seropositivity was statistically associated to miscarriage $\left(\mathrm{OR}=2.45, \mathrm{CI}_{95}=1.56-\right.$ 3.87, $P<0.001)$. The OR of having miscarriage increased up to $2.76\left(\mathrm{CI}_{95}=1.61-4.73, \mathrm{P}<0.001\right)$ in seropositive women with a low concentration of anti-Toxoplasma antibodies $(\mathrm{OD} \leq 0.75)$, compared to that in Toxoplasma-negative group. The OR of having miscarriage in high-titer group (OD $>0.75)$ was 2.04 $\left(\mathrm{CI}_{95}=1.04-4.00, P=0.038\right)$. According to the results from logistic regression, there was a direct association between miscarriage history and age of mothers. The OR of miscarriage increased by $1.94\left(\mathrm{CI}_{95}=1.45-2.61\right)$ for every five years increase in age of mothers.

Results from the multiple logistic regression analysis showed that the association between Toxoplasma-seropositivity and having miscarriage history was statistically significant $\left(\mathrm{OR}=2.63, \mathrm{CI}_{95}=1.64-4.19, P<0.0001\right)$ after controlling for effects of the age of mothers in the model. Moreover, the OR of having miscarriage history in high-titer and low-titer groups of Toxoplasma-seropositive women was $2.06\left(\mathrm{CI}_{95}=1.04-4.1, P=0.04\right)$ and 3.24 $\left(\mathrm{Cl}_{95}=1.85-5.68, \mathrm{P}<0.0001\right)$ respectively, compared to that in seronegative women. No significant association was found between the concentration of anti-Toxoplasma antibodies and the miscarriage history in seropositive women $\left(\mathrm{OR}=0.74, \mathrm{CI}_{95}=0.34-1.6, P=0.45\right)$. In addition, association between the history of miscarriage and sex of the neonates were not statistically significant $(\mathrm{OR}=1.01$, $\mathrm{CI}_{95}=0.67-1.54, P=0.9$ ).

Association of latent toxoplasmosis with maternal age at pregnancy was assessed using analysis of variance in a subset of primiparous women. Totally, 412 (48.4\%) primiparous women were included in the current study. The estimated mean age for IgG-positive and IgG-negative primiparous women with no history of miscarriage included $25.93\left(\mathrm{Cl}_{95}=25.04-26.82\right)$ and $26.4\left(\mathrm{Cl}_{95}=25.98-\right.$ 26.83), respectively. Analysis of variance showed no significant differences between the two mean values $(P=0.58)$.

\section{Discussion}

The dormant stage of $T$. gondii infection in humans is characterized by the presence of tissue cysts in brain and other organs. From the clinical point of view, these life-long tissue cysts are almost asymptomatic in infected individuals [8]. In recent years, effects of asymptomatic latent toxoplasmosis in human life have been investigated [8]. Possible relationships of latent toxoplasmosis with mental disorders such as schizophrenia [25], Alzheimer's disease [26] and cognitive disorder [27] have been studied in humans and animal models. Increased reaction times [28] in Toxoplasma-infected individuals may explain the high-rate traffic accidents by these patients [29]. Toxoplasma gondii can affect personality of the infected patients [8]. The T. gondii infected men are nearly $3 \mathrm{~cm}$ taller than $T$. gondii free men, having further muscles and dominant faces. These differences may be associated with different testosterone levels in $T$. gondii positive and $T$. gondii negative men [30,31]. Effects of $T$. gondii infection on endocrine and immune systems have been demonstrated repeatedly and their association with secondary sex ratio is not surprising [32]. According to results of the study by Flegr et al., latent toxoplasmosis has surprisingly serious effects on public health. Furthermore, $T$. gondii is one of the most important factors affecting variation of offspring sex ratio over the world [33].

Results of the present study have shown that $T$. gondii infection is significantly associated with having male neonates and that the association is statistically significant. The OR of having male neonates in T. gondii seropositive women was approximately $64 \%$ higher than that in seronegative women. A retrospective cohort study in Czech Republic (1996-2004) has shown that of 1803 neonates, the secondary sex ratio increased in 454 Toxoplasma-positive women (percentage of males = 0.608), compared to 1349 Toxoplasma-negative women (percentage of males $=0.527 ; P=0.0027$ ) [16]. In the current study, the OR of having male neonates increased in women with high-titer anti-Toxoplasma IgG as the value of 1.64 in seropositive women reached 2.10 in women with high-titer antibodies. A similar study by Kankova et al. (2007) showed that women with high concentration of anti-Toxoplasma IgG gave birth to 250 male neonates per 100 female neonates, while women with low concentration of anti-Toxoplasma of IgG gave birth more female than male neonates [16]. In experimental models, mice with $T$. gondii infection had a greater sex ratio, compared to control group [17]. Increased sex ratio could be explained by the effects of latent toxoplasmosis on immunosuppression mechanisms in mice and humans [34], as the secondary sex ratio is affected by significant modulation of immune responses and cytokine production in infected mice. Toxoplasma parasite could rescue male fetuses with developmental disorders by inducing immunosuppression mechanisms [35].

Seroprevalence of toxoplasmosis in women with abortion events has been recorded high (17-43.8\%) in African and Asian countries [36-38]. In the present study, relatively high seroprevalence (34.3\%) of $T$. gondii 
infection was detected in cord blood serum samples of women with miscarriage history and the relationship between these two parameters was statistically significant. The odds of having miscarriage was approximately two and a half times higher for the seropositive women than for the seronegative women. The OR of having miscarriage increased to the value of 2.76 in low-titer seropositive women, compared to that in seronegative control group. The OR of having miscarriage in high-titer group was only 2.04. Moreover, the association between presence of anti-Toxoplasma IgG and miscarriage history in seropositive women was not statistically significant. Similar findings were reported by Sharf et al., 1973; Mahajan et al., 1976; Sahwi et al., 1995 and Al-Hamdani, 1997 [39-42]. In a study by Alvarado-Esquivel et al. (2016) in Mexico, association of Toxoplasma infection and abortion in pregnant women of rural areas with high seropositivity rate was reported [43]. In 2011, Pavlinova et al. recorded $42.1 \%$ anti-Toxoplasma IgG seropositivity in 530 women with recurrent miscarriage which were significantly $(P<0.0004)$ greater than that in control groups (25.1\%) [44]. In a study by Turbadkar et al., bad obstetric history (BOH) was recorded in $42.1 \%$ of Toxoplasma seropositive women [45]. In the present study, history of miscarriage in pregnant women and secondary sex ratio of offspring were statistically linked to $T$. gondii infection.

\section{Conclusion}

In conclusion, $T$. gondii infection affects secondary sex ratio in humans and can be addressed as one of the major miscarriage reasons in women.

\section{Abbreviations \\ BOH: Bad obstetric history; ELISA: Enzyme-linked immunosorbent assay: HRP: Horseradish peroxidase; IBM: International business machines corporation; IgG: Immunoglobulin G; OD: Optical density; OPD: Ortho phenylenediamine; OR: Odds ratio; PBST: Phosphate buffered saline, tween 20; SPSS: Statistical package for the social sciences}

\section{Acknowledgements}

The authors would like to thank staff within Mostafa Khomeini Hospital, Tehran, Iran, for their useful help. We would like to acknowledge all staff from the toxoplasmosis laboratory (Department of Medical Parasitology and Mycology, Tehran University of Medical Sciences, Tehran, Iran) for their useful collaboration.

\section{Availability of data and materials}

The datasets generated and/or analysed during the current study are publicly available in the Figshare repository, https://figshare.com/s/ 3e92ca38f0bdc9c28c2e.

\section{Authors' contributions}

SS and HK coordinated the experiments and provided important advice for the experiments and financial support. AT and SJA carried out the experiments. AT gathered the information of women's medical records and SN analyzed the data. AT drafted the original manuscript and all authors read and approved the final version of the manuscript.

\section{Ethics approval and consent to participate}

The current study was approved by the Ethical Committee of Tehran University of Medical Sciences, Tehran, Iran. Informed written consent was obtained from all participants before being involved in the study. All participants signed an informed consent and received a complete copy of the signed consent form.

\section{Consent for publication}

Not applicable (no individual person's data).

\section{Competing interests}

The authors declare that they have no competing interests.

\section{Publisher's Note}

Springer Nature remains neutral with regard to jurisdictional claims in published maps and institutional affiliations.

\section{Author details}

'Department of Medical Parasitology and Mycology, School of Public Health, Tehran University of Medical Sciences, P.O. Box: 1417613191, Pour Sina Street, Ghods Avenue, Enghelab Avenue, Tehran, Iran. ${ }^{2}$ Students Scientific Research Center, Tehran University of Medical Sciences, Tehran, Iran. ${ }^{3}$ Department of Epidemiology and Biostatistics, School of Public Health, Tehran University of Medical Sciences, Tehran, Iran.

Received: 3 August 2017 Accepted: 29 June 2018

Published online: 05 July 2018

\section{References}

1. Dubey JP. Toxoplasmosis of animals and humans. 2rd ed. New York: CRC Press Inc. Boca Raton; 2010. p. 1-313.

2. Sharbatkhori M, Moghaddam YD, Pagheh AS, Mohammadi R, Mofidi HH, Shojaee S. Seroprevalence of Toxoplasma gondii infections in pregnant women in Gorgan City, Golestan Province, Northern Iran. Iran J Parasitol. 2014;9:181-7.

3. Mahmoudvand H, Saedi Dezaki E, Soleimani S, Baneshi MR, Kheirandish F, Ezatpour B, Zia-ali N. Seroprevalence and risk factors of Toxoplasma gondii infection among healthy blood donors in southeast of Iran. Parasite Immunol. 2015;37(7):362-7.

4. Tenter AM, Heckeroth AR, Weiss LM. Toxoplasma gondii: from animals to humans. Int J Parasitol. 2000;30:1217-58.

5. Weiss LM, Dubey JP. Toxoplasmosis: a history of clinical observations. Int J Parasitol. 2009;39(8):895-901.

6. Selseleh M, Keshavarz H, Mohebali M, Shojaee S, Selseleh M, Eshragian MR, Mansouri F, Modarressi MH. Production and evaluation of Toxoplasma gondii recombinant GRA7 for serodiagnosis of human infections. Korean J Parasitol. 2012;50:233-8.

7. Hill D, Dubey JP. Toxoplasma gondii: transmission, diagnosis and prevention. Clin Microbiol Infect. 2002;8:634-40

8. Flegr J, Escudero DQ. Impaired health status and increased incidence of diseases in Toxoplasma-seropositive subjects - an explorative cross-sectional study. Parasitology. 2016;143:1974-89. https://doi.org/10.1017/ S0031182016001785.

9. Davis DL, Gottlieb MB, Stampnitzky JR. Reduced ratio of male to female births in several industrial countries: a sentinel health indicator? JAMA. 1998; 279(13):1018-23.

10. Jacobsen R, Moller $\mathrm{H}$, Mouritsen A. Natural variation in the human sex ratio. Hum Reprod. 1999;14:3120-5.

11. James WH. Evidence that mammalian sex ratios at birth are partially controlled by parental hormone levels at the time of conception. J Theor Biol. 1996;180:271-86.

12. James WH. Sex ratio of offspring of diabetics. Lancet. 1998;351:773.

13. Rjasanowski I, Kloting I, Kovacs P. Altered sex ratio in offspring of mothers with insulin-dependent diabetes mellitus. Lancet. 1998:351:497-8.

14. Chacon-Pugnau GC, Jaffe K. Sex ratio at birth deviations in modern Venezuela: the Trivers-Willard effect. Soc Biol. 1996;43:257-70.

15. Dama MS, Novakova LM, Flegr J. Do differences in Toxoplasma prevalence influence global variation in secondary sex ratio? Preliminary ecological regression study. Parasitology. 2016;143:1193-203. 
16. Kankova S, Sulc J, Nouzova K, Fajfrlik K, Frynta D, Flegr J. Women infected with parasite Toxoplasma have more sons. Naturwissenschaften. 2007:94:122-7.

17. Kankova S, Kodym P, Frynta D, Vavrinova R, Kubena A, Flegr J. Influence of latent toxoplasmosis on the secondary sex ratio in mice. Parasitology. 2007;134:1709-17.

18. Kimball AC, Kean BH, Fuchs $F$. The role of toxoplasmosis in abortion. Am J Obsest Gynecol. 1971;111:219-26.

19. Giorgino FL, Mega M. Toxoplasmosis and habitual abortion. Our expedice. Clin Exp Obstet Gynecol. 1981;8:132-4.

20. Quablan HS, Jumaian N, Abu-Salem A, Hamadelil FY, Mashagbeh M, AbdelGhani F. Toxoplasmosis and habitual abortion. J Obstet Gynaecol. 2002;22: 296-8.

21. Hillyer GV, Soler de Galanes M, Rodriguez-Perez J, Bjorland J, Silva de Lagrava M, Ramirez Guzman S, et al. Use of the falcon assay screening testenzyme-linked immunosorbent assay (FAST-ELISA) and the enzyme-linked immunoelectrotransfer blot (EITB) to determine the prevalence of human fascioliasis in the Bolivian Altiplano. Am J Trop MedHyg 1992; 46(5): 603-609. [PubMed: 1599055]

22. Teimouri A, Jafarpour Azami S, Keshavarz H, Esmaeili F, Alimi R, Ayazian Mavi S, Shojaee S. Anti-Toxoplasma activity of various molecular weights and concentrations of chitosan nanoparticles on tachyzoites of $\mathrm{RH}$ strain. Int J Nanomedicine. 2018;13:1341-51.

23. Teimouri A, Modarressi MH, Shojaee $\mathrm{S}$, et al. Detection of toxoplasmaspecific immunoglobulin $G$ in human sera: performance comparison of in house dot-ELISA with ECLIA and ELISA. Eur J Clin Microbiol Infect Dis. 2018:1-9. https://doi.org/10.1007/s10096-018-3266-y

24. Corp Released IBM. IBM SPSS statistics for windows, version 21.0. Armonk, NY: IBM Corp; 2012.

25. Alipour A, Shojaee S, Mohebali M, Tehranidoost M, Abdi Masoleh F, Keshavarz $\mathrm{H}$. Toxoplasma infection in schizophrenia patients: a comparative study with control group. Iranian J Parasitol. 2011;6(2):31-7.

26. Mahmoudvand $H$, Sheibani V, Shojaee S, Mirbadie SR, Keshavarz $H$, Esmaeelpour K, Keyhani AR, Ziaali N. Toxoplasma gondii infection potentiates cognitive impairments of Alzheimer's disease in the BALB/C mice. J Parasitol. 2016;102(6):629-35.

27. Mahmoudvand H, Ziaali N, Aghaei I, Sheibani V, Shojaee S, Keshavarz H, Shabani M. The possible association between Toxoplasma gondii infection and risk of anxiety and cognitive disorders in BALB/C mice. Pathogen Glob Health. 2016;109(8):369-76.

28. Havlicek J, Gasova Z, Smith AP, Zvara K, Flegr J. Decrease of psychomotor performance in subjects with latent "asymptomatic" toxoplasmosis. Parasitology. 2001;122:515-20.

29. Flegr J, Klose J, Novotna M, Berenreitterova M, Havlicek J. Increased incidence of traffic accidents in Toxoplasma-infected military drivers and protective effect RhD molecule revealed by a large-scale prospective cohort study. BMC Infect Dis. 2009; https://doi.org/10.1186/1471-2334-972.

30. Hodkova H, Kolbekova P, Skallova A, Lindova J, Flegr J. Higher perceived dominance in Toxoplasma infected men a new evidence for role of increased level of testosterone in toxoplasmosis-associated changes in human behavior. Neuroendocrinol Lett. 2007:28:110-4.

31. Zouei N, Shojaee S, Mohebali M, Keshavarz H. The association of latent toxoplasmosis and level of serum testosterone in humans. BMC Res Notes. 2018; https://doi.org/10.1186/s13104-018-3468-5.

32. James $\mathrm{WH}$. Offspring sex ratio at birth as markers of paternal endocrine disruption. Environ Res. 2006;100:77-85.

33. Flegr J, Hoffmann R, Dammann M. Worse health status and higher incidence of health disorders in rhesus negative subjects. PLoS One. 2015;10(10):e0141362.

34. Kankova S, Holan V, Zajicova A, Kodym P, Flegr J. Modulation of immunity in mice with latent toxoplasmosis-the experimental support for the immunosuppression hypothesis of Toxoplasma-induced changes in reproduction of mice and humans. Parasitol Res. 2010;107:1421-7.

35. Flegr J, Striz I. Potential immunomodulatory effects of latent toxoplasmosis in humans. BMC Infect Dis. 2011;11:274.

36. Attia RA, el-Zayat MM, Rizk H, Motawea S. Toxoplasma lgG \& IgM antibodies. A case control study. J Egypt Soc Parasitol. 1995;25:877-82

37. Pal RA, Qayyum M, Yaseen M. Seroprevalence of antibodies to Toxoplasma gondii, with particular reference to obstetric history of patients in Rawalpindi-Islamabad, Pakistan. J Pak Med Assoc. 1996:46:56-8.
38. Gogate A, Deodhar LP, Shah PK, Vaidya P. Detection of Chlamydia trachomatis antigen \& Toxoplasma gondii (lgM) \& Mycoplasma hominis (lgG) antibodies by ELISA in women with bad obstetric history. Indian J Med Res. 1994;100:19-22.

39. Sharf M, Eibschitz I, Eylan E. Latent toxoplasmosis and pregnancy. Obstet Gynecol. 1973:42(3):349-54

40. Mahajan RC, Gupta I, Chhapra MB, Gupta AN, Devi PK, Ganguli NK. Toxoplasmosis -its role in abortion. Indian J Med Res. 1976;64(6):797-800.

41. Sahwi SY, Zaki MS, Haiba NY, Elsaid OK, Anwar MY, Abdrabbo SA. Toxoplasmosis as a cause of repeated abortion. Asia Oceania J Obstet Gynaecol. 1995:21(2):145-8.

42. Al-hamdani MM, Mahdi NK. Toxoplasmosis among women with habitual abortion. East Mediterr Health J. 1997:3(2):310-5.

43. Alvarado-Esquivel C, Torres-Castorena A, Liesenfeld O, García-López CR, Estrada-Martinez S, Sifuentes-Alvarez A, Marsal-Hernandez JF, Esquivel-Cruz R, Sandoval- Herrera F, Castaneda JA, Dubey JP. Seroepidemiology of Toxoplasma gondii infection in pregnant women in rural Durango, Mexico. J Parasitol. 2009;95:271-4.

44. Pavlinova J, Kincekova J, Ostro A, Saksun L, Vasilkova Z, Konigova A. Parasitic infections and pregnancy complications. Helminthologia. 2011;48:8-12.

45. Turbadkar D, Mathur M, Rele M. Seroprevalence of torch infection in bad obstetric history. Indian J Med Microbiol. 2003:21:108-10.

\section{Ready to submit your research? Choose BMC and benefit from:}

- fast, convenient online submission

- thorough peer review by experienced researchers in your field

- rapid publication on acceptance

- support for research data, including large and complex data types

- gold Open Access which fosters wider collaboration and increased citations

- maximum visibility for your research: over $100 \mathrm{M}$ website views per year

At BMC, research is always in progress.

Learn more biomedcentral.com/submissions 